\title{
Os espaços não formais em cena: uma carta àqueles que defendem a educação em ciências e a Amazônia
}

Adana Teixeira Gonzaga adanatg05@gmail.com Universidade do Estado do Amazonas (UEA), Manaus, Amazonas, Brasil

\section{Ana Caroline Lima de Souza} souzaana30@gmail.com Universidade do Estado do Amazonas (UEA), Manaus, Amazonas, Brasil

Rafael Gonçalves de Brito rafael.gbrito33@gmail.com Universidade do Estado do Amazonas (UEA), Manaus, Amazonas, Brasil

Caroline Barroncas de Oliveira carol barroncas@yahoo.com.br Universidade do Estado do Amazonas (UEA), Manaus, Amazonas, Brasil

Mônica de Oliveira Costa mwmcosta@gmail.com

Universidade do Estado do Amazonas (UEA), Manaus, Amazonas, Brasil

\begin{abstract}
RESUMO
No presente artigo nos propomos problematizar como o fechamento de espaços não formais atinge a Educação Científica, especificamente o Bosque da Ciência, a partir de uma carta redigida por professores-pesquisadores que ensinam-pesquisam sobre o ensino de Ciências no Ensino Fundamental. Para esta discussão, pautada na Pesquisa Narrativa elegemos a carta como meio de nos comunicar com a sociedade e explicitar todos os retrocessos e prejuízos que o fechamento desse espaço não formal representa para o Ensino de Ciências, a Pesquisa em Ciências, a Educação Científica na Amazônia e para todo e qualquer sujeito que se interesse pelo bem comum, pois essa escrita nos move para a luta em prol da popularização da Educação em Ciências. Na carta, apresentamos uma breve reflexão sobre o Bosque da Ciência como um espaço educativo, a partir de nossas memórias, revisitadas por lembranças e produções oriundas das vivências acadêmicas. Nesse movimento reflexivo, observamos que são relevantes as interações sociais no processo de socialização e divulgação científica efetivados no ambiente formativo, dando destaque ao processo humanizador, ao ensino contextualizado e ao acesso à informação situada na área da Educação Científica. Nossas narrativas vivificam e dão novos sentidos ao que poderia ser somente uma mera descrição de um espaço físico, constituindo-se num ambiente onde se ancoram pensamentos sobre o ser e o fazer docente que ensina-pesquisa Ciências.
\end{abstract}

PALAVRAS-CHAVE: Espaços não-formais. Educação Científica. Ensino Fundamental. 


\section{INTRODUÇÃO}

\section{"A ciência é um diálogo com a natureza"}

Ilya Prigogine

A História da Matemática e a Etnomatemática são duas, entre outras, tendências do campo da Educação Matemática. Porém, apresentam caminhos de pesquisas, problemas de investigação e referenciais teóricos distintos e, na maior parte das vezes, independentes. A História da Matemática é a tendência que estuda "[...] fatos, datas e nomes associados à geração, à organização intelectual e social e à difusão do conhecimento - no nosso caso conhecimento matemático através das várias culturas ao longo da evolução da humanidade." (D'AMBROSIO, 2000, p. 241). A Etnomatemática analisa os "[...] modos, estilos, artes, técnicas, de explicar, aprender, conhecer, lidar com o ambiente natural, social, cultural e imaginário." (D'AMBROSIO, 2007, p. 2).

Se em outros tempos a afirmativa de Prigogine seria uma justificativa para altos investimentos em Ciência, nos dias atuais, vivemos uma realidade na qual os objetos das ciências são hierarquizados a partir de um suposto grau de importância para a sociedade. Desse modo, se antes "compreender a natureza foi um dos grandes projetos do pensamento ocidental" (PRIGOGINE, 1996, p. 157), atualmente a ciência dita científica e necessária é aquela que atende às exigências do sistema econômico. Entre as diversas possibilidades de pesquisas realizadas em ambas tendências, neste artigo considera-se apenas às relacionadas aos processos de ensino e de aprendizagem da Matemática nos anos iniciais do Ensino Fundamental. O mapeamento teórico realizado por Omena (2015) sobre História da Matemática, e o mapeamento teórico de Santos, Lara, Lima e Ferreira (2017) sobre Etnomatemática, apresentam um panorama sobre tais pesquisas.

Esse cenário produziu uma realidade fragilizada na qual as questões políticas passam por momentos críticos, visto que o bem comum se restringe a uma pequena parcela de brasileiros que decidem por nós em quais setores deve ser investido o dinheiro público. Agregado a isso um pensar social precário e diminuído principalmente quando deveríamos manter as ações coletivas e não somente individuais, um clima de ódio e intolerância para aquele que discorda, indaga e critica todos esses acontecimentos nos últimos 6 anos no Brasil.

Nos caminhos percorridos pela ciência conseguimos enxergar que não existe apenas um único caminho de se fazer ciência, mas sim vários modos de abordá-la, pelo simples fato de se pensar ciência não em sua totalidade, mas em suas várias fragmentações do saber (BATISTA; MOCROSKY; MONDINI, 2017).

Toda essa realidade nos leva a viver um momento de reflexão, especialmente na própria ideia do que é ciência, pois se antes ela era vista como aquela que tratava das leis eternas, hoje "temos a necessidade de se pensar a ciência com posturas mais holísticas - isto é, uma ciência que contemple aspectos históricos, dimensões ambientais, posturas éticas e políticas" (CHASSOT, 2004, p. 257). Ou seja, falar de Ciência é muito mais que discutir teorias, é olhar para os efeitos dos seus resultados, para as pessoas, para os problemas causados, como bem sintetiza Chassot (2004, p.259):

Queremos o direito de ser informados e debater sobre o assunto. E isso precede a qualquer manipulação cujos resultados ainda não são conhecidos. 
Não podemos nos submeter às ditaduras de mercado, que visam lucros imediatos. Queremos um planeta saudável e isso é buscar, também, um mundo com menos fome.

Falar de Ciência é buscar também um mundo no qual as pesquisas voltadas para a educação sejam valorizadas e colocadas como prioridade no país. Entretanto, os princípios que cercam tal área são afetados durante esse processo de caos político e econômico, no qual recursos estão sendo cortados, benefícios sendo retirados de universidades e institutos públicos no Brasil. Na realidade manauara isso também é evidenciado quando se tem notícias de que espaços não formais (institucionalizados ou não) foram fechados por falta de recursos, como as que foram expostas em jornais digitais como A Crítica, G1 AM, entre outras.

Assim, começamos a nos questionar: quanto esses locais públicos são importantes tanto para a formação inicial e continuada de professores/pesquisadores, como também para a aprendizagem de milhares de alunos em Ciências? Como vivências em locais de pesquisa e ensino podem movimentar questionamentos de luta social?

Dessa forma, este trabalho tem como objetivo geral: Problematizar como o fechamento desses espaços não formais atinge a Educação Científica, especificamente o Bosque da Ciência, a partir de uma carta redigida por professores-pesquisadores que ensinam-pesquisam sobre o ensino de Ciências no Ensino Fundamental.

Para esta discussão, elegemos a carta como meio de nos comunicar com a sociedade e explicitar todos os retrocessos e prejuízos que o fechamento desse espaço não formal representa para o Ensino de Ciências, a Pesquisa em Ciências, a Educação Científica na Amazônia e para todo e qualquer sujeito que se interesse pelo bem comum. Uma vez que:

Escrever cartas é escrever-se. Muito além de simplesmente encurtar distâncias físicas, pode ser a formulação de pensamentos ou a expressão de sentimentos [...] que não puderam ser verbalizados por motivos diversos, como o profundo desejo de ver materializado o abstrato (ZANI, 2018, p.117).

Considerando a situação levantada e o desconhecimento da sociedade sobre o caso, temos o propósito de, enquanto investigadores narrativos, problematizar e refletir sobre a importância desse espaço educativo em nossas vidas. Para isso, perpassamos pelos princípios da pesquisa qualitativa, que em tese se relaciona com o ambiente que se vive buscando sempre se questionar sobre o que é vivido e presenciado no mundo (ESTEBAN, 2010).

Assumimos a perspectiva da Pesquisa narrativa, pois é o estudo da forma como "nós seres humanos experimentamos o mundo", entendendo que "somos organismos contadores de histórias", tanto professores quanto alunos são contadores e personagens de suas próprias vivências e dos demais, histórias pessoais e sociais (CONNELLY; CLANDININ, 1995, p.11). Diante da investigação narrativa deparamo-nos com experiências formativas na docência em Educação em Ciências nos espaços não formais, a partir do entendimento de que o narrar nos forma e nos possibilita caminhos formativos na relação consigo, com o outro e com o ambiente experienciado.

Nós e o espaço do Bosque da Ciência estamos inter-relacionados por meio de nossas histórias de vida, pois fomos atravessados por ele em muitos momentos 
formativos - tanto em passeios familiares quanto em nossa formação acadêmica (graduação e pós-graduação). Por esse entendimento, consideramos nossas memórias formativas na ressignificação desse ambiente em sua dimensão social, cultural, política e econômica e por meio da carta ela se presta ao mesmo tempo à preservação de memória e registro, à discussão e ao posicionamento em relação a questões por vezes controversas e à comunicação de tudo o que diz respeito à pesquisa - processos, lições aprendidas, saberes e conhecimentos produzidos ao pensar a Educação em Ciências no Ensino Fundamental (DOLZ; SCHNEUWLY, 2004).

Na busca de compor um cenário problematizador e reflexivo para você leitor, iremos dialogar com a perspectiva de não desumanização do sujeito, em que os temas discutidos e sistematizados pela academia não têm fim em si mesmos, consideramos o sujeito em sua totalidade, em suas emoções carregadas de sentido, reconhecendo a autonomia e a capacidade em se apropriar dos saberes ancorados sob uma lente crítica da realidade que o cerca a fim de modificá-la, repensá-la em um movimento criador.

\section{REVISITANDO O BOSQUE DA CIÊNCIA}

O Bosque da Ciência é um espaço de divulgação científica, educação e lazer. Possui uma área aproximada de treze hectares, e está localizado no perímetro urbano da cidade de Manaus (imagem 1), na Zona Central - Leste, foi inaugurado em 1으 de abril de 1995, pelo Instituto Nacional de Pesquisas da Amazônia - INPA.

Figura 1 - Entrada do Bosque da Ciência

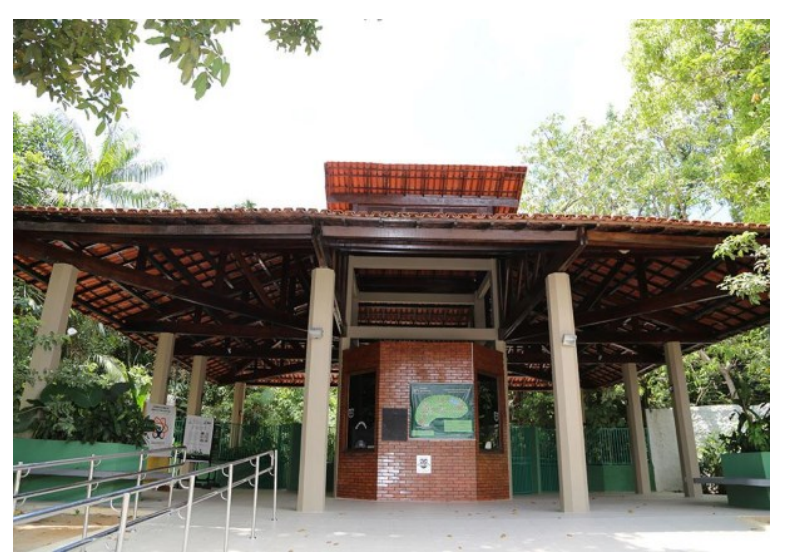

Fonte: INPA (2015).

De acordo com as observações feitas, a infraestrutura desse espaço carece de investimentos em manutenção, conservação e acessibilidade, no entanto ao se levar em conta a grande variedade de possibilidades ali encontradas para se trabalhar temas relacionados ao ensino de Ciências, a infraestrutura do Bosque ainda é capaz de atender a essas demandas.

Página | 330

Por ser uma área que se localiza no perímetro urbano, permite o acesso das escolas com os estudantes até esse espaço, pode ser utilizado para a implementação de projetos relacionados ao Ensino de Ciências. No que tange ao seu espaço físico em si, o Bosque tem uma área bem ampla e conta com vários 
espaços onde podem ser abordados conteúdos diferenciados que se relacionam às ciências.

O bosque possui uma beleza ímpar, realizar uma visita nesse espaço nos permite ter acesso a informações acerca do mesmo: estrutura, espécies que o compõem, resultados de pesquisas realizadas pelo INPA. Tudo isso promove um grande momento de aprendizado como fonte de riqueza para a vida pessoal, acadêmica e profissional, além de possibilitar o desenvolvimento da educação ecológica.

A partir do que foi visto podemos perceber a grande variedade de contribuições que uma ida a esse espaço pode propiciar aos educandos transpondo o caráter educativo e contribuindo para o próprio desenvolvimento pessoal.

Em relação às estratégias que poderiam ser adotadas utilizando o Bosque das Ciências elas devem estar direcionadas, levando em conta que trata-se de um espaço-não-formal, ou seja, essas atividades devem ser dinâmicas buscando fugir daquelas rotineiramente propostas no espaço da sala de aula como podemos ver em Mota et al. (2014, p. 194):

\begin{abstract}
A estratégia de utilizar o Bosque da Ciência para promover a aprendizagem dos conceitos científicos justifica-se por entendermos que ela permite: ampliar o capital cultural do aluno; romper com a perspectiva disciplinar promovendo o trabalho interdisciplinar; articular o conhecimento com o meio ambiente, favorecendo, dessa forma, a contextualização; flexibilizar o currículo; motivar tanto alunos quanto professores no processo ensino aprendizagem; divulgar a ciência, a tecnologia e a alfabetização científica.
\end{abstract}

Como visto existem várias perspectivas que podem ser abordadas ao se pensar estratégias educativas a serem implementadas durante uma visita a esse espaço cabendo ao professor o entendimento para mediar esse processo.

Cada espaço do Bosque das Ciências encerra em si uma riqueza de detalhes e possibilidades que permitem trabalhar os mais variados tipos de temáticas em diferentes níveis de ensino, como por exemplo os seres vivos com a vantagem de explorar a fauna amazônica, propiciando ao estudante conhecimentos sobre várias espécies da nossa região, de acordo com o que encontramos em Branco, Souza e Terán (2015, p. 1-4):

Em se tratando de um animal difícil de encontrar no seu habitat natural, podemos ter um contato mais próximo e compreender mais sobre sua forma de vida. Ao observar o "peixe-boi" despertamos para várias curiosidades sobre sua história natural: alimentação, reprodução, etc. Muitas vezes estas curiosidades são manifestas quando o aprendiz está em contato direto com o objeto de estudo.

Apresentamos a seguir alguns espaços que podem ser encontrados nesse local e trabalhados na perspectiva que estamos descrevendo (INPA, 2015):

TANQUE DOS PEIXE-BOIS: É uma das principais atrações do bosque. Nesse local é possível ver os peixe-bois amazônicos, mamíferos que vivem em água doce, chegam a medir entre 2,8 a 3m de comprimento e a pesar $450 \mathrm{~kg}$. Esses animais encontram-se classificados como espécie "vulnerável" pela UICN (2000).

CASA DA CIÊNCIA: A casa da ciência é um local onde se pode encontrar uma exposição sobre o estilo de vida ribeirinho, animais empalhados, o ninho de um gavião-real, uma folha de Coccoloba com 2,50m de altura, entre outros. 
ILHA DA TANIMBUCA: No centro da ilha é possível encontrar uma enorme árvore da tanimbuca com mais de 600 anos, além de quelônios e diversos peixes, entre eles, o poraquê que antes encontrava-se em outra parte do bosque.

TRILHA SUSPENSA: É uma passarela que leva os visitantes por cima de uma área de difícil acesso para que possam observar a flora local.

TRILHA EDUCATIVAS: O bosque possui diversas trilhas por onde os visitantes podem se aventurar e nas quais é possível encontrar diversas placas com informações sobre as plantas encontradas no caminho, como mostra a figura 2.

Figura 2 - Trilhas educativas

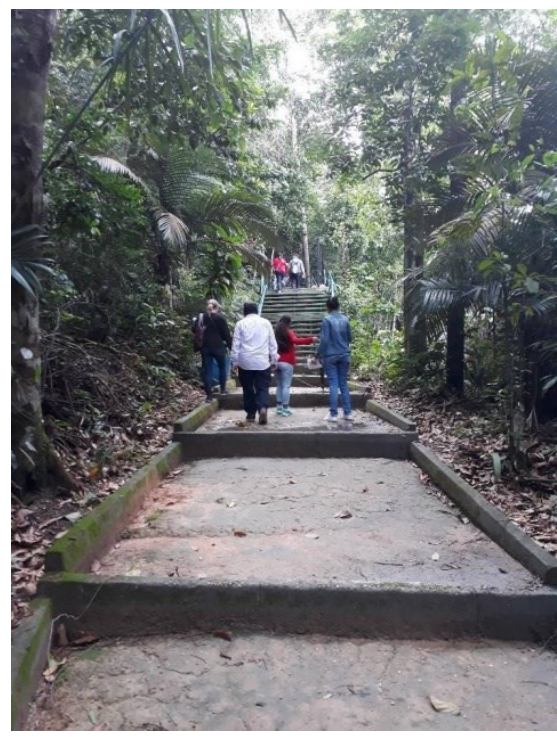

Fonte: Autoria própria (2018).

LAGO AMAZÔNICO: Nesse lago, encontram-se alguns quelônios, peixes e plantas aquáticas amazônicas, figura 3.

CEQUA: O Centro de Estudos de Quelônios da Amazônia é um local muito interessante, nele os visitantes podem observar inúmeras espécies de quelônios como o mata-mata, o tracajá e o cabeçudo, como mostra a figura 3.

Figura 3 - Espécies de quelônios encontradas no CEQUA

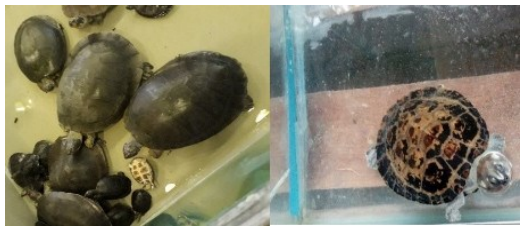

Fonte: Autoria própria (2018).

A dinâmica do trabalho existente no Bosque da Ciência, na perspectiva de uma Página | 332 instituição de educação não formal, aproxima-se da concepção apontada por Gohn (1999) no sentido de envolver sujeitos conscientes de seu papel na sociedade. Nesse sentido, é importante salientar que os espaços formativos que contribuem para a formação do sujeito no campo da educação não-escolar sempre coexistiram com o campo da educação escolar, "sendo mesmo possível imaginar sinergias 
pedagógicas muito produtivas e constatar experiências com intersecções e complementaridades várias" (AFONSO, 2001, p.31). Assim, compartilhamos com Afonso (2001), que a educação não-escolar não pode ser construída contra a escola, nem servir a quaisquer estratégias de destruição dos sistemas públicos de ensino, como parecem pretender algumas ideias postas da ideologia neoliberal.

Então, com o desejo de ampliarmos os horizontes de leitura e percebermos outras produções, outros modos de escrever que nos desnudam enquanto docentes, pesquisadores, pessoas ao explorarmos outros caminhos em busca de diálogo. Ao tomar as experiências dialógicas do pesquisar e ensinar em Educação em Ciências no Ensino Fundamental tentamos usar a escrita de uma carta como instrumento de problematização e divulgação do Ensino de Ciências, para que você tenha um momento de reflexão sobre esse acontecimento e suas relações com o direcionamento da nossa sociedade. Uma vez que,

\begin{abstract}
Escrever é mostrar-se, dar-se a ver, fazer aparecer o rosto próprio junto ao outro. [...] A carta é simultaneamente um olhar que se volta para o destinatário (por meio da carta que recebe ele se sente olhado) e uma maneira de o remetente se oferecer ao seu olhar pelo que de si mesmo the diz. De certo modo, a carta proporciona um face-a-face. [...] A carta que, na sua qualidade de exercício, trabalha no sentido da subjetivação do discurso verdadeiro, da sua assimilação e da sua elaboração como bem próprio, constitui também e ao mesmo tempo uma objetivação da alma (FOUCAULT, 1992, p.145).
\end{abstract}

Essa exposição pessoal fala como fomos e estamos sendo subjetivados. São verbalizações singulares de como nesse processo de constituição docente de professores em Educação em Ciências nos anos iniciais e finais do Ensino Fundamental fomos atravessados pelas memórias formativas que revelam como passado e presente estão relacionados à constituição do ser professor(a) de Ciências. A partir das questões históricas que nos possibilitaram perceber outros modos de ser e estar na docência mostra a multiplicidade que os espaços não formais atuam como eixo formativo na Educação em Ciências.

Assim, iremos tecer uma carta à sociedade amazonense, bem como para todo cidadão brasileiro, considerando nossas memórias, possibilidades de pensar/refletir sobre questões relacionadas ao Ensino de Ciências, pois esta escrita nos move para a luta em prol da popularização da Educação em Ciências. É neste sentido, que encaminhamos a seguinte carta aberta.

\title{
A CARTA QUE NOS MOVE PARA A LUTA EM PROL DA EDUCAÇÃO CIENTÍFICA
}

\section{CARTA À SOCIEDADE AMAZONENSE}

Manaus, dias cinzas com previsão de raios verde-esperança, de 2019

Cara sociedade amazonense,

Página | 333

Nós, professores-pesquisadores, enquanto parte integrante da sociedade amazonense, presenciamos situações que têm nos inquietado nos últimos tempos como: os cortes de verbas na educação e na pesquisa, perda de direitos trabalhistas, a negação da veracidade de dados disponibilizados por institutos de 
pesquisas entre outros acontecimentos sociais, econômicos e políticos. Questões que nos movem para um pensar mais problematizador de como se vive e sobre a importância "da responsabilidade de quem se arrisca a ser ao mesmo tempo testemunha e narrador de sua época." (BRUM, 2019, p. 07). Questões políticas têm nos levado a um movimento de revolução e luta por causas coletivas, pois muitas vezes temos acesso a notícias que nos causam sentimentos de ira, tristeza e decepção.

Assim, diante da situação política do País, o sentimento de insegurança se instala em meio a nós, enquanto professores-pesquisadores da Educação Básica e da formação inicial de professores. Ao vivenciarmos tudo o que vem acontecendo no âmbito político nos causa profunda consternação a ponto de refletir se vale a pena continuar investindo em uma formação visando a carreira docente, se a mesma tem sido tratada com total desmazelo pelo atual ocupante do cargo máximo do país. Até porque você, que é um sujeito desta sociedade, precisa saber que a Educação em Ciências não é uma preocupação apenas da comunidade científica, mas uma questão de política pública, pois se deposita alta carga de responsabilidade à escola enquanto lugar onde o saber sistematizado é desenvolvido e construído em vez de somente "repassado", sem cogitar sobre a que política este modelo de educação está atendendo (COLLINS, 1999; ZIMAN, 1999; VILANOVA; MARTINS, 2008).

Sentimentos esses que podem estar sendo compartilhados por todos aqueles que se preocupam com o futuro e que enxergam na educação um dos pilares preponderantes para que esse futuro seja alcançado de maneira sustentável e que seja assegurado a todas as gerações vindouras do nosso país. Pois, a Ciência deve ser compreendida a partir de uma visão mais ampla de mundo, o que resulta considerar seus processos de construção numa dimensão de formação cidadã do indivíduo. Logo, é preciso saber como vai se formar esse professor, para que ele educado cientificamente, também eduque seu aluno, fazendo-o reconhecer o mundo de modo diferente. Nessa perspectiva, o documento "Declaração sobre Ciência e o Uso do Conhecimento Científico" (UNESCO/Budapeste, 1999), afirma que:

a) A educação científica, no sentido amplo, sem discriminação e englobando todos os níveis e modalidades, é um pré-requisito fundamental para a democracia e para assegurar-se o desenvolvimento sustentável;

b) Os professores de todos os níveis e as pessoas envolvidas na educação científica informal devem ter acesso a uma constante atualização dos seus conhecimentos, para maximizar a sua atuação nas atividades educacionais;

c) Novos currículos, metodologias de ensino e recurso, levando em conta o gênero e a diversidade cultural, devem ser desenvolvidos por sistemas nacionais de educação, em reação às necessidades educacionais em mudança na sociedade;

d) As instituições educacionais devem fornecer educação científica básica aos estudantes de outras áreas que não ciências. Devem também fornece oportunidades para a aprendizagem contínua (por toda a vida) no campo das Ciências. 
Esse tipo de reflexão tem levado diversos países a implementar programas educacionais inovadores, visando à alfabetização científica da população. E o nosso caso? Você consegue apontar avanços atuais em relação a esses itens? Como vamos nos posicionar diante desses retrocessos?

Corriqueiramente temos pesquisado e estudado temas voltados para uma educação libertadora a qual possibilita um olhar crítico sobre a realidade ao nosso redor. E, no caso dos amazônicos, essa se relaciona diretamente com o meio ambiente e tudo que o implica: sua valorização, preservação e sustento de nossas vidas. A educação para esse público não deve ser neutra, apolítica e isenta das responsabilidades sociais e de humanização. Trata-se de uma educação dialógica em que deve haver "amor e humildade" (FREIRE, 2002, p.80). O diálogo e a dialogicidade baseados nessas condições são essenciais em uma educação como prática da liberdade, numa educação ancorada nos princípios da educação popular. Liberdade que requer incessante busca que é uma conquista e não uma doação (FREIRE, 2002, p.34). Uma liberdade que possibilite a criação, admiração e capacidade de aventurar-se (FREIRE, 2002, p.55).

Mais recentemente fomos surpreendidos com a notícia de que o Bosque das Ciências, local que faz parte da história do povo amazonense, paralisaria as suas atividades de visitação do público externo em razão do não repasse de verbas por parte do governo federal, o que tornou insustentável a manutenção do local e a remuneração dos funcionários.

De acordo com notícias de veículos de informações do estado do Amazonas (A crítica e Amazonas atual) o Instituto Nacional de Pesquisas da Amazônia (INPA) anunciou, em 09 de julho de 2019, o fechamento das portas do Bosque da Ciência para a visitação pública. Para aqueles que desejavam visitar o local, era cobrado o valor de $\mathrm{R} \$ 5,00$, o qual era depositado em uma conta do governo federal. No entanto, esse valor, não estava sendo repassado para a administração do Bosque ocasionando os problemas acima descritos.

Quem, quando criança, não visitou o Bosque em excursão escolar ou em passeio familiar nos finais de semana? Esse local traz lembranças que fazem parte da formação de um sentimento de pertença à nossa cultura, em especial à nossa floresta, tão rica em cores e diversidade de espécies. Nesse local, conhecemos de perto animais em risco de extinção e aprendemos a importância de cuidar e preservar o meio ambiente.

Você deve estar se perguntando: Mas o que são espaços não formais? Como o Bosque da Ciência atua na Divulgação-Educação Científica?

A relação do Ensino de Ciências com os mais diversos espaços não formais presentes em Manaus acaba por possibilitar uma experiência que vai além da formalidade encontrada em uma sala de aula conseguindo tornar bem mais rico os processos cognitivos dos alunos. De acordo com os estudos de Lorenzetti e Delizoicov (2001, p.7): cidadãos necessitam, deverá, ao longo da escolarização, propiciar iniciativas para que os alunos saibam como e onde buscar os conhecimentos que necessitam para a sua vida diária. Os espaços não formais compreendidos como museu, zoológico, parques, fábricas, alguns programas de televisão, Internet, entre outros, além daqueles formais, tais como bibliotecas escolares 
e públicas, constituem fontes que podem promover uma ampliação do conhecimento dos educandos. As atividades pedagógicas desenvolvidas que se apoiam nesses espaços, em aulas práticas, saídas a campo, feiras de ciências, por exemplo, poderão propiciar uma aprendizagem significativa contribuindo para um ganho cognitivo.

Esses espaços tornam-se ambientes ricos em possibilidades educacionais, principalmente quando possuem a perspectiva de divulgação científica que traz o acesso a conceitos científicos tornando possível a alfabetização científica, isso é o que o Bosque da Ciência proporciona para a sociedade manauara e todo aquele que defenda a popularização da Ciência. A parceria entre escola e outros espaços educativos pode conferir maior significado aos estudos da ciência, pela simples razão de que eles possuem recursos capazes de aproximar e despertar o interesse e o olhar científico do estudante, estimular a curiosidade o desejo pela ciência e por possibilitar uma aproximação com o objeto a ser estudado, considerando que isso poderá acontecer se houver a mediação e a intencionalidade do professor. Segundo Pinto e Figueiredo (2010, p. 3):

O espaço não formal pode, mediante a sua estrutura física, fornece recursos didáticos para o aprendizado que a escola não possui. Dependendo da percepção do aluno, ele pode analisar informações relevantes em um espaço não formal de ensino, onde, na escola, um determinado tema abordado relacionado a esse espaço informal, não foi adequadamente informado, ou não teve a intenção de ser transmitido em profundidade.

A discussão trazida aqui tem o intuito de reconhecer a importância de espaços não formais para ações educacionais, e o quanto, educacionalmente falando, os estudantes, professores e membros sociais estariam perdendo com o fechamento desses espaços de educação não formal. Nesse contexto Zancan (2000, p. 6) defende que, "os membros da comunidade científica brasileira têm hoje mais uma tarefa: lutar para mudar o ensino, de informativo para transformador e criativo". Esse é um grande desafio, pois abarca todos os níveis de ensino sem privilegiar um em detrimento de outro. Mas, quando nos deparamos com estas questões políticas e econômicas que justificam as decisões tomadas pelo nosso representante ficamos nos questionando se nós, enquanto sociedade, temos clareza das tomadas de decisão feitas. Vamos à luta!

Ainda que nem todos tenhamos a formação voltada para o ensino de ciências da natureza, temos conosco a certeza de que o Bosque da Ciência é um ambiente fundamental para o desenvolvimento humano, a fomentação de pesquisas e a formação de estudantes em idades diversas. Bem como expõe Morhy et al. (2016, p. 114) "o Bosque da Ciência contribui para que o indivíduo interaja com o meio ambiente, despertando sentimentos e emoções, estimulando-o para uma nova consciência ambiental, e formação do conhecimento científico". Desse modo, precisamos conhecê-lo para compreendermos todas as aprendizagens e experiências que ele proporciona.

Temos em si uma determinada relação com esses lugares, que nos fazem Página | 336 conectar sentimentos que desconhecíamos. O Bosque da Ciência nos faz ter essas percepções emocionais que perpassam pela alegria, dúvida, deslumbre em um só lugar. Todas essas concepções nos fazem pensar quão importantes são esses lugares para a formação e principalmente para os processos de afloramento de sentimentos de cada ser humano. 
Sob essa perspectiva, durante a disciplina Fundamentos da Educação em Ciências, realizada na Universidade do Estado do Amazonas pelo Programa de Pósgraduação em Educação e Ensino de Ciências na Amazônia, fomos ao Bosque da Ciência participar de uma aula prática, durante a qual vivenciamos momentos ímpares para nossa formação acadêmica e profissional.

Tal atividade pode ser descrita a partir do conceito de experiência de Larrosa (2002), que descreve uma experiência como sendo algo que nos passa e não está do lado da ação, da prática ou da técnica, mas do lado do parar e sentir, por isso que ela nos solicita atenção, escuta, abertura, disponibilidade, exposição e vulnerabilidade. Trazemos a narrativa do desenvolvimento da atividade e os efeitos que elas causaram em nós.

Logo na entrada do Bosque, o professor da disciplina fez uma parada em frente a algumas árvores, entre elas uma seringueira, na qual aproveitou o momento para contar parte da história do Amazonas. Em uma segunda árvore, algo se mexendo nos galhos chamou nossa atenção: uma iguana. Que surpresa e que novidade! Pensávamos que eram macacos e não sabíamos que as iguanas subiam tão alto em árvores.

Em uma segunda parada, tivemos um encontro magnífico com um mamífero aquático endêmico da Amazônia, que é conhecido na região com o nome de peixeboi. Localizados em tanques gigantes, mantivemos um contato mais próximo com esses animais, trazendo à tona sentimentos de proteção para com esta espécie, surgindo também questionamentos que tinham referências com a sua alimentação, surgimento do seu nome, seu tamanho, entre outros.

Esses animais estão presentes na lista de risco de extinção, nesse caso o Bosque das Ciências faz o processo de acolhimento destes animais, bem como o cruzamento das espécies para novas gerações. Toda essa vivência colabora para que a aprendizagem ocorra significativa e isso só é possível se houver a interação entre o meio circundante, natural e social (DELIZOICOV, ANGOTTI e PERNAMBUCO, 2011), por isso é necessário tornar esses ambientes parte da realidade em que vivemos.

Durante a caminhada tivemos contato com estudos desenvolvidos por pesquisadores do INPA através de banners com resumos de artigos científicos. Isso nos deixou bastante satisfeitos, pois podemos conhecer os objetos sobre os quais têm se debruçado os pesquisadores, além do acesso aos resultados das pesquisas. Apontamos essa questão como salutar, pois mesmo que alguns termos técnicos ou em outra língua dificulte a compreensão do público em geral, é necessário que seja mostrado para a sociedade onde está sendo investidos os recursos públicos. De acordo com Bueno (2010, p.6), "a comunicação científica, devidamente recodificada e retrabalhada, contribui para alimentar o processo de divulgação científica".

O bosque nos movimenta para encontros inesquecíveis, que perpassam pelo reconhecimento de espécies vegetais ou animais, como a Sumaúma que é uma árvore conhecida em terreno amazônico e admitida como uma das maiores árvores do mundo, podendo atingir até 60 metros de altura. Nesse mesmo local também nos relacionamos com macacos, para os quais mostramos alimentos a fim de que chegassem mais pertos de nós. Essa conexão com a natureza, e tudo que dela brota, faz-nos entender o que é dito por Ubaldo et al. (2018) quando retrata 
o homem e a natureza como um sistema orgânico tendo uma base de relação holística, de inteira relação de não dependência, o que já veio se modificando durante o passar dos anos.

O Bosque da Ciência pode nos proporcionar ainda vivências para o interior da floresta, ou seja, que nos permite o encontro com a terra, com espécie vegetais, bem como os vários sons que a natureza pode nos proporcionar acionando perspectivas cognitivas dos alunos envolvidos. Esses processos cognitivos afetam a percepção, a memória, a aprendizagem, a linguagem, a inteligência, o raciocínio, a consciência, processos de atenção, criatividade e emoções (GONÇALVES, 2012).

Os quelônios também fizeram parte desse percurso. Fomos até o Cequa, onde encontramos diversas espécies, entre elas o mata-mata (cágado de água doce), sendo esse o que mais nos despertou curiosidade dentre os demais animais que lá se encontravam, uma vez que possui aparência exótica, lembrando-nos uma rocha.

Saindo do Cequa, existe um viveiro de jabutis, espécie de quelônio terrestre, ao qual também fizemos uma visita a fim de alimentá-los. Essa experiência nos despertou mais profundamente para o cuidado que devemos ter com a natureza, uma vez que também fazemos parte dela e nossa existência depende do zelo, inclusive, com as menores espécies. Levando-nos ao encontro do objetivo do ensino de ciências que é manter o diálogo crítico e a busca para resolver problemas que podem atingir a sociedade, incluindo ainda a relevância de cada indivíduo para a amplificação do bem-estar social (COUTINHO, MATOS e SILVA, 2014).

Dentro do viveiro dos jabutis, existe um portão que dá acesso ao espaço onde se encontram o jacaré-açu, maior réptil sul-americano. O zelador do local, estando conosco, resolveu abrir o portão para que pudéssemos vê-lo sem a interferência das grades que o rodeavam. Sem adentrar o local, somente olhando do portão, pudemos ver somente sua cabeça repousando na beira do lago onde se encontrava imerso. Uma mistura de sensações que nos envolveu: medo, admiração, curiosidade e deslumbramento.

O que esse lugar nos causa é o reconhecimento de um equilíbrio ambiental que com o dia a dia esquecemos que existe ao nosso redor, que auxilia na nossa sobrevivência e nosso bem estar estando completamente conectados. Por isso existe a necessidade de envolver conhecimentos sobre a educação ambiental nos alunos, pelo simples fato de que esse conhecimento tem o princípio de luta por um ato político que pensa em uma revolução social que se volta para uma percepção holística que relaciona homem, natureza e universo (JACOBI, 2003).

A educação ambiental, o ensino de Ciências e Ciências Naturais podem ser envolvidos nesses espaços educativos, onde proporcionam com muito mais complexidade problematizações de nossa própria consciência ambiental e de como nos relacionamos com o meio ao nosso redor reafirmando o que é descrito por Afonso et al. (2016, p. 109) "indivíduos com níveis de consciência ambiental mais elevada fundamentariam suas decisões de acordo com o impacto que elas exercem no meio ambiente".

Página | 338

Chegando ao fim do percurso, fomos até a llha da Tanimbuca - árvore com mais de 600 anos que fica no centro da ilha e mede, aproximadamente, 35 metros de altura. No encerramento das atividades, o professor da disciplina reuniu todos os estudantes ao redor da árvore para abraçá-la. Mais um gesto de cuidado pela natureza, o qual vivenciamos nesse dado momento. 
De acordo com Guimarães (2016, p.12), durante a Rio 92, a Educação Ambiental para a sustentabilidade equitativa foi reconhecida como "um processo de aprendizagem permanente baseado no respeito a todas as formas de vida". Nesse sentido, esse percurso vivenciado no Bosque da Ciência, cara Sociedade, nos proporcionou o contato com a natureza que não temos em nosso cotidiano, levando-nos ao despertar para o respeito e o cuidado com o meio ambiente.

Mais recentemente tivemos a notícia de que o Bosque da Ciência foi reaberto no dia 13 de julho de 2019, segundo os portais de notícias (Em Tempo, G1 AM, entre outros) com a ajuda do prefeito da cidade de Manaus Arthur Virgílio Neto, que oficializou ações emergenciais para manter o funcionamento no bosque da ciência. O que nos leva ao questionamento: até quando essa ação irá vigorar?

Nós, enquanto professores em formação em um curso que possui uma linha voltada para a questão da utilização dos espaços não formais enquanto ferramenta e ensino, ficamos muito preocupados com o possível encerramento das atividades do Bosque da Ciência para a visitação pública tendo em vista a grande quantidade de atividades de ensino, bem como de artigos e dissertações ali produzidos voltados para a utilização dos espaços não formais para o ensino, sobretudo de ciências.

O que temos que levar em conta com o fechamento do Bosque, é exatamente essa grande quantidade de conhecimento que deixará de ser produzido. Conhecimento esse que não pode ser apenas visto sob o prisma míope da quantidade de material produzido, como medir o efeito que causa em qualquer estudante participar de uma atividade especialmente voltada para a sua aprendizagem em um ambiente mais do que propício para a realização da mesma, você deve pensar nas consequências de permitir que decisões baseadas apenas em questões econômicas, muitas das vezes tomadas por pessoas sem a menor percepção do que vem a ser a educação em um ambiente assim.

Os espaços não formais de ensino acabam por possibilitar outros caminhos para a aprendizagem além dos tradicionais desenvolvidos geralmente dentro da sala de aula. Como afirma Araújo, Silva e Terán (2011, p. 2):

\footnotetext{
Ao refletirmos sobre o Ensino de Ciências, percebemos que há prevalência da memorização e transmissão de conceitos repassados de geração em geração e na maioria das vezes, desconectados da realidade dos estudantes. Essa abordagem tem sua origem numa concepção positivista cartesiana que concebe o ensino, o homem e a sociedade como parte de um todo, sem articulação entre si.
}

Esses espaços tornam-se ambientes ricos em possibilidades educacionais, principalmente quando possuem a perspectiva de divulgação científica que trazem o acesso a conceitos científicos tornando possível a alfabetização científica, isso é o que o Bosque da Ciência proporciona para a sociedade manauara.

A discussão trazida aqui tem o intuito de reconhecer a importância de espaços não formais para ações educacionais, e o quanto, educacionalmente falando, os estudantes, professores e membros sociais estariam perdendo com o fechamento desses espaços de educação não formal.

Há muitas décadas, a Educação Científica, no Brasil, revela-se crítica. Com a expansão dos sistemas de ensino e a crescente centralidade do conhecimento, é 
requerida, hoje, uma cultura científica mínima não apenas para atender às mudanças tecnológicas, mas também para melhorar a vida em sua integralidade. Assim, o direito ao conhecimento e a uma Educação Científica de qualidade passou a ser um imperativo do nosso tempo.

Convocamos a todos, a reivindicarmos nosso direito à Educação Científica, reverberada pelo espaço do Bosque da Ciência como um lugar mobilizador e potencializador de conhecimentos científicos, sociais e culturais. Uma vez que, termos acesso a esses elementos formativos é uma das maiores alternativas de mudança e resistência em prol de uma educação que valoriza a docência e o processo de ensino na área de Ciências e da Cidadania. 


\title{
Non-formal spaces on the scene: a letter to those who defend science education as well as the Amazon
}

\begin{abstract}
In this article, we propose discuss about how the closing of non-formal spaces affect the Scientific Education, especially the Bosque da Ciência, starting of a letter wrote by teachersresearches that learning-searching about Science Teaching in Elementary School. To this discuss which is supported on Narrative Research, we choose the letter as means to us communicate with Society and to make all backlashes explicit and losses that the closing of this non-formal space represent to Science Teaching, to Research in Science, to Scientific Education on the Amazon and to every people that appreciate mutual benefit, because this writing move us to struggle in favor to popularization of Science Education. In this letter, we present a short reflection about Bosque da Ciência as an education space, starting of our memories which was revisited by associations and productions from academic moments. In this reflective movement, we observe that social interactions are considered relevant in the process of socialization and scientific divulgation that are to carry out on the formative environment giving highlight to humanization process, to contextualized teaching and to access of information situated on Scientific Education area. Our narratives give life and new senses to what could been just a simple physical space description which constituting itself in an environment where thinking is ground on the to be and to do of teacher who teachingresearch Science.
\end{abstract}

KEYWORDS: Non-formal spaces. Scientific Education. Elementary School. 


\section{REFERÊNCIAS}

AFONSO, A. J. Os lugares da educação. In: VON SIMSON, O.R.M. (org) Educação Não Formal: Cenários de Criação. Campinas: São Paulo. Editora da UNICAMP/ Centro de Memória, 2001.

AFONSO, T.; ZANON, M. A. G.; LOCATELLI, R. L.; AFONSO, B. P. D. Consciência ambiental, comportamento pró-ambiental e qualidade de gerenciamento de resíduos em serviço de saúde. Revista de Gestão Ambiental e Sustentabilidade GeAS, v. 5, n. 3. 2016.

ARAÚJO, J. N.; SILVA, C. C.; TERÁN, A. G. A floresta amazônica: um espaço não formal em potencial para o ensino de ciências. In: VIII Encontro Nacional de Pesquisa em Educação em Ciências - ENPEC. Campinas, 2011. Disponível em: http://files.ensinodeciencia.webnode.com.br/200000320-

bebefbfbb1/2011_A\%2OFloresta\%20Amaz\%C3\%B4nica_Um\%20Espa\%C3\%A7o\%2 ON\%C3\%A30\%20Formal\%20em\%20Potencial\%20para\%20o\%20Ensino\%20de\%20 Ci\%C3\%AAncias.pdf. Acesso em: 29 mar. 2018.

BATISTA, J. O.; MOCROSKY, L. F.; MONDINI, F. Sujeito e objeto na produção do conhecimento científico. ACTIO, Curitiba, v. 2, n. 3, p. 44-59, 2017. Disponível em: https://periodicos.utfpr.edu.br/actio/.

BRANCO, A. K. A. M.; SOUZA. D.; TERÁN, A. F. O bosque da ciência: ambiente de aprendizagem para o ensino de ciências. Latin American Journal of Science Education, n. 2, p. 1- 8, 2015.

BRUM, Eliane. Brasil, construtor de ruínas - Um olhar sobre o país, de Lula a Bolsonaro. Porto Alegre: Arquipélago Editorail, 2019.

BUENO, W. C. Comunicação Científica e Divulgação Científica: aproximações e rupturas conceituais. Inf. Inf., Londrina, v. 15, n. esp, p. 1 - 12, 2010. Disponível em: <dx.doi.org/10.5433/1981-8920.2010v15nesp.p1>. Acesso em: 17 de abril de 2018.

CHASSOT, Attico. A ciência através dos tempos. 2. Ed. Reform. São Paulo: Moderna, 2004.

COLLINS, H. A comunidade científica em tempos de disputa. In: GIL, F. (Coord.). A ciência tal qual se faz. Lisboa: Sá da Costa, 1999. p. 53-64.

COM POUCOS FUNCIONÁRIOS, BOSQUE DA CIÊNCIA FECHA PARA VISITAÇÃO. Portal A crítica, Manaus, 08, Julho e 2019. Disponível em: $<$ https://www.acritica.com/channels/manaus/news/com-poucos-funcionariosbosque-da-ciencia-fecha-para-visitacao-em-manaus>. EM MANAUS. G1 AM, Manaus, 09, Julho e 2019. Disponível em: https://g1.globo.com/am/amazonas/noticia/2019/07/09/visitas-ao-bosque-daciencia-estao-suspensas-a-partir-desta-terca-9-em-manaus.ghtml. 
CONNELLY, F. M. E CLANDININ, D.J. Relatos de Experiência e Investigación Narrativa In: LARROSA, J. (org). Déjame que te cuente. Ensayos sobre narrativa y educación. Barcelona: Editorial Laertes, 1995.

DANTAS, G. Bosque da Ciência reabre para visitação pública neste sábado (13). Em tempo, Manaus, 13, Julho e 2019. Disponível em: https://d.emtempo.com.br/amazonas/164373/bosque-da-ciencia-reabre-paravisitacao-publica-neste-sabado-13.

NASCIMENTO, E. Bosque da Ciência em Manaus reabre ao público após ser fechado por falta de recursos para o funcionamento. G1 AM, Manaus, 13, Julho e 2019. Disponível em:

https:/g1.globo.com/am/amazonas/noticia/2019/07/13/bosque-da-ciencia-emmanaus-reabre-ao-publico-apos-ser-fechado-por-falta-de-recursos-parafuncionamento.ghtml.

COUTINHO, F. A.; MATOS, S. A.; SILVA, F. A. R. Aporias dentro do movimento Ciência, Tecnologia, Sociedade e Ambiente. Apontamentos para uma solução. Revista da SBEnBio, n.7, 2014.

DELIZOICOV, D.; ANGOTTI, J. A.; PERNAMBUCO, M. M. Ensino de Ciências: fundamentos e métodos. 4 ed. São Paulo: Cortez, 2011.

DOLZ, J.; SCHNEUWLY, B. Gêneros e progressão em expressão oral e escrita elementos para reflexões sobre uma experiência suíça (francófona). In: SCHNEUWLY, B.; DOLZ, J. et al. Gêneros orais e escritos na escola. Campinas, SP: Mercado de Letras, 2004.

FOUCAULT. M. O que é um autor? Portugal: Veja/Passagens, 1992.

FREIRE, P. Pedagogia do oprimido. 34 ed. São Paulo: Paz e Terra, 2002.

GOHN, M. G. Educação não-formal e cultura política: Impactos sobre o associativismo do terceiro setor. São Paulo, Cortez. 1999.

GONÇALVES, T. N. R. Ciência da educação e ciências cognitivos contributos para uma abordagem transdisciplinar. Revista Portuguesa de Educação, v. 25, n. 1, p. $217-239,2012$.

GUIMARÃES, M. Por uma educação ambiental crítica na sociedade atual. Revista Margens Interdisciplinar, 7(9), 11-22, 2016.

INPA - INSTITUTO NACIONAL DE PESQUISA NA AMAZÔNIA. Bosque da Ciência. Manaus: INPA, 2015. Disponível em: http://bosque.inpa.gov.br/bosque/index.php/homepage/sobre. Acesso em: 13 ago. 2019. 
JACOBI, P. Educação ambiental, cidadania e sustentabilidade. Cadernos de Pesquisa, n. 118, p. 189-205, 2003.

LARROSA, Jorge. Notas sobre a experiência e o saber de experiência. Revista Brasileira de Educação, n. 19, 2002.

LORENZETTI, L.; DELIZOICOV, D. Alfabetização científica no contexto das séries. Ensaio - Pesquisa em educação em ciências, v.3, n.1, p. 45 - 61, 2001. Disponível em: http://www.fae.ufmg.br/ensaio/v3_n1/leonir.PDF. Acesso em: 07 nov. 2009.

MORHY, P. E. D.; TERAN, A. F.; SOUZA, S. A.; NEGRAO, F. C. . Usos da biodiversidade amazônica no bosque da ciência para fins educativos. ARETÉ (Manaus), v. 9, p. 108-115, 2016.

MOTA, Denise et al. PRÁTICAS PARA O ENSINO DA QUÍMICA E MATEMÁTICA NO ESPAÇO NÃO FORMAL BOSQUE DA CIÊNCIA. Revista Areté | Revista Amazônica de Ensino de Ciências, [S.I.], v. 7, n. 13, p. 193-203, maio 2017. ISSN 1984-7505. Disponível em: http://periodicos.uea.edu.br/index.php/arete/article/view/114. Acesso em: 01 abr. 2018.

PINTO, L. T.; FIGUEIREDO, V. A. O ensino de Ciências e os espaços não formais de ensino: um estudo sobre o ensino de Ciências no município de Duque de Caxias/RJ. In: II Simpósio Nacional de Ensino de Ciência e Tecnologia. Paraná, 2010. ISSN: 2178-6135

PRIGOGINE, llya. O fim das certezas: tempo, caos e as leis da natureza (Tradução: Roberto Leal Ferreira). São Paulo: Editora da Universidade Estadual Paulista, 1996.

UBALDO, B. M.; FERREIRA, M. J. C.; VASCONCELOS, R. A.; VIANA, M. M. C. Evolução histórica do processo de ruptura entre o homem e a natureza. Revista Interdisciplinar em Cultura e Sociedade (RICS), v. 4, n. e., p. 383 - 393, 2018.

UNESCO. Declaracion sobre la ciencia y el uso del saber cientifico. Budapeste, 1999. Disponível em:

http://www.unesco.org/science/wcs/esp/declaracion_s.htm. Acesso em: 25 jul. 2009.

VILANOVA, R.; MARTINS, I. Educação em ciências e educação de jovens e adultos: pela necessidade do diálogo entre campos e práticas. Ciência e educação, v.14, n.2, p. 331-346, 2008.

ZANCAN, G. T. Educação científica uma prioridade nacional. São Paulo em perspectiva, São Paulo, v.14, n.1, p. 1-7, 2000.

ZANI, Tina. A poesia na ação poética de escrita de cartas. Linha mestra, n.36, p.116-119, 2018.

Página | 344 ZIMAN, J. A ciência na sociedade moderna. In: GIL, F. (Coord.). A Ciência tal qual se faz. Lisboa: Sá da Costa, 1999. 
Recebido: 24 ago. 2019

Aprovado: 09 dez. 2019

DOI: $10.3895 /$ actio.v4n3.10595

Como citar: GONZAGA, A.T.; SOUZA, A. C. L. de; BRITO, R. G. de; OLIVEIRA, C. B. de; COSTA, M. de O.

Os espaços não formais em cena: uma carta àqueles que defendem a educação em Ciências e a Amazônia. ACTIO, Curitiba, v. 4, n. 3, p. 327-345, set./dez. 2019. Disponível em: <https://periodicos.utfpr.edu.br/actio>.

Acesso em: XXX

Correspondência:

Adana Teixeira Gonzaga

Rua Mutum do Norte, n. 35, Bairro: Tarumã Açu, Manaus, Amazonas, Brasil. CEP: 69023-097.

Direito autoral: Este artigo está licenciado sob os termos da Licença Creative Commons-Atribuição 4.0

Internacional.

(c) (1)

Página | 345 